\title{
Measuring continuity in the era of technology-enabled care
}

\author{
James C Bohnhoff, Dheepa Sekar, \\ Aimee Pickering, Tiffany Yang, \\ Maryam Zamanian, Galen E Switzer
}

\begin{abstract}
CONTINUITY OF CARE (or simply, 'continuity'), which Haggerty et al define as the degree to which a patient experiences their care as 'coherent $[, . .$. connected and consistent with [their] medical needs and personal context', has been recognised as a feature of high-quality medical care, especially primary care, for more than half a century. ${ }^{1}$ Recent studies have reinforced this consensus, with data associating continuity with increased patient ${ }^{2}$ and provider $^{3}$ satisfaction, decreased cost of care ${ }^{4}$ and even decreased mortality. ${ }^{5}$ However, measuring, tracking and improving continuity remains a significant challenge, in part because of the subjectivity and complexity of the patient-provider relationship. In addition, technological advancements in healthcare delivery may threaten the validity of existing measures of continuity. Here we review existing measures of patientexperienced continuity of care, discuss how they are affected by technologyrelated changes to healthcare and suggest avenues for future research on continuity.
\end{abstract}

\section{Components of continuity}

Continuity is a subjective, multidimensional experience of patients. Haggerty et al described continuity as a combination of informational continuity (knowledge of a patient's history), management continuity (consistent medical management) and relational continuity (therapeutic providerpatient relationship). ${ }^{1}$ Longitudinality (frequent or sustained interaction between a provider and a patient, which may be measured objectively) is not a component of continuity per se but may be an important facilitator of or even prerequisite for a patient's sense of continuity. ${ }^{6}$ These terms are described in Table 1.

\section{Current measures of continuity}

A patient's subjective sense of continuity is most intuitively assessed through self-report. As reviewed by Ball et al, ${ }^{7}$ several self-report instruments have been developed, with different surveys emphasising different aspects of continuity but without the emergence of one clear gold standard. These instruments have their limitations: as with any self-reported measure of human perceptions or behaviour, it is critical to re-examine the measurement properties (eg reliability and validity) of these measures when they are applied to new populations and care settings. In addition, because they must be collected prospectively from individual patients, self-report instruments are labour intensive.

Utilisation indices are efficient methods of measuring longitudinality and are often used as an alternative means of describing continuity. These are objective measures that calculate a score on the basis of a patient's frequency of visits with a given provider (or providers), a patient's total visits and sometimes other factors such as duration of care. Examples of common utilisation indices are summarised in Table 2, but many more have been introduced and were well summarised by Jee and Cabana. ${ }^{8}$ Because utilisation indices for continuity can be calculated retrospectively on the basis of patient report or medical records, they can be applied relatively easily to any population or care setting. ${ }^{9}$ Although these measures of longitudinality assess continuity only indirectly, they have nonetheless been consistently shown to correlate with positive clinical outcomes. ${ }^{5}$

\section{Continuity and technology- enabled care}

Recent technology-related changes in the practice of medicine will have a profound effect on both the provision and measurement of continuity. Thanks in part to expanded telehealth support in response to the COVID-19 pandemic, ${ }^{10}$ patients today may supplement in-person consultations with telephone or audiovisual telehealth, and they may also communicate with their providers asynchronously through apps or secure text or email communication. These novel ways to connect may contribute to patients' sense of continuity in ways that are not captured by traditional measures. Self-report measures of continuity 


\section{Table 1. Key terms}

\begin{tabular}{|c|c|c|c|c|}
\hline \multicolumn{2}{|l|}{ Term } & Definition & $\begin{array}{l}\text { Subjective } \\
\text { or objective? }\end{array}$ & Collection method \\
\hline \multicolumn{2}{|c|}{ Continuity of care } & $\begin{array}{l}\text { Care connected, consistent, in line with a patient's } \\
\text { needs and personal context }\end{array}$ & Subjective & Self-report instruments* \\
\hline \multirow[t]{3}{*}{$\begin{array}{l}\text { Types of } \\
\text { continuity }\end{array}$} & Informational & $\begin{array}{l}\text { Care based on information from a patient's prior } \\
\text { history and circumstances }\end{array}$ & & \\
\hline & Management & $\begin{array}{l}\text { Consistent management in accordance with a patient's } \\
\text { needs }\end{array}$ & & \\
\hline & Relational & Therapeutic provider-patient relationship & & \\
\hline \multicolumn{2}{|c|}{ Longitudinality } & $\begin{array}{l}\text { Frequent or sustained interactions between a provider } \\
\text { and a patient }\end{array}$ & Objective & $\begin{array}{l}\text { Self-report or utilisation } \\
\text { data }\end{array}$ \\
\hline
\end{tabular}

${ }^{*}$ For further descriptions of self-report instruments, refer to Ball et al, $2018^{7}$

\section{Table 2. Example utilisation indices}

\begin{tabular}{llc}
\hline Name & Description & Definition* \\
\hline $\begin{array}{l}\text { Usual Provider of Care } \\
\text { (UPC) }\end{array}$ & $\begin{array}{l}\text { What proportion of a patient's visits } \\
\text { was with their usual provider? }\end{array}$ & $\frac{n_{u}}{M}$ \\
\hline $\begin{array}{l}\text { Continuity of Care } \\
\text { (COC) }\end{array}$ & $\begin{array}{l}\text { Were a patient's visits concentrated } \\
\text { among fewer providers or spread out } \\
\text { across more? }\end{array}$ & $\frac{\sum_{i=1}^{M}\left(n_{i}{ }^{2}\right)-M}{M(M-1)}$ \\
\hline $\begin{array}{l}\text { Sequential Continuity } \\
\text { of Care (SECON) }\end{array}$ & $\begin{array}{l}\text { How likely was the patient to see the } \\
\text { same provider for a subsequent visit? }\end{array}$ & $\frac{\sum_{j=1}^{M-1} \Phi_{j}}{M-1}$
\end{tabular}

${ }^{*} n_{u}$ is the number of visits made to a designated usual provider. $M$ is the total number of visits in the study period. $n_{i}$ is the total number of visits to provider $i$. $\Phi_{j}$ is equal to 1 if visit $j$ and $j+1$ are conducted with the same provider, 0 otherwise.

developed before telehealth often assess continuity using questions that imply only the option of face-to-face encounters, as when the Chao Perception of Continuity scale asks how often patients 'see the same doctor when [they] go for medical care'. ${ }^{11}$ Faced with such questions, respondents who achieve significant relational continuity through technology-enabled communication or visits may misrepresent and underrepresent their sense of continuity. Similarly, utilisation indexes generally calculate longitudinality on the basis of in-person consultations only, overlooking entirely the contributions of technology-facilitated interactions.
Shared electronic health records (EHRs) allow providers (even new ones) to provide care based on a patient's prior history and treatment plans, ${ }^{12}$ which may increase informational and management continuity without longitudinality. These continuity benefits of shared EHRs would likely be reflected in self-reported continuity measures but would have no effect on the longitudinality calculations of utilisation indices.

\section{Future directions}

By facilitating informational and management continuity between multiple providers, and by facilitating all forms of continuity without in-person longitudinality, shared EHRs and technology-enabled doctor-patient interactions, respectively, violate some of the assumptions underpinning current continuity measures. In response, we suggest three research aims to update the measurement of continuity. First (1), self-reported measures should be adapted to become inclusive of technology-enabled care. They might ask, for example, whether patients 'interact with the same doctor when receiving medical care'. With these updated measures, once appropriately validated, it may be possible to confidently assess patients' sense of informational, relational and management continuity in practices that incorporate technologyenabled care and to (2) compare continuity with and without telehealth and other technologies in order to quantify the degree to which these additions contribute to continuity. Finally (3), utilisation indices should also be updated to incorporate the continuity effects of technology-enabled care. This might at first mean treating telehealth visits as 'in-person equivalents'. However, in time the work described above would facilitate the creation of utilisation indices that 'value' different interactions, from in-person consultations to SMS messages, according to their contributions to continuity.

Some of the same technologies we suggest evaluating may themselves 
facilitate these three ambitious research aims. EHRs can compile a complete and objective log of patients' care, facilitating the calculation of utility indices without relying on faulty patient recall. Technologies such as check-in kiosks, ${ }^{13}$ secure text messaging ${ }^{14}$ and smartphone applications ${ }^{15,16}$ are increasingly used to communicate with and collect information from patients, which might include continuity self-reports. Even with these tools, there is extensive work to be done to understand how patients experience continuity in a modern healthcare environment. We contend that these efforts will be worthwhile. As long as continuity remains an important component of quality healthcare, updated, valid tools to measure continuity should be of interest to practices, health systems and governmental organisations alike.

\section{Authors}

James C Bohnhoff MD, Clinician-Research Fellow, Department of Pediatrics, University of Pittsburgh School of Medicine, Pittsburgh, PA, USA

Dheepa Sekar MD, Clinical Instructor, Division of General Internal Medicine, University of Pittsburgh School of Medicine, Pittsburgh, PA, USA

Aimee Pickering MD, Clinical Instructor, Division of General Internal Medicine, University of Pittsburgh School of Medicine, Pittsburgh, PA, USA

Tiffany Yang MD, Assistant Professor of Pediatrics, Department of Pediatrics, University of Pittsburgh School of Medicine, Pittsburgh, PA, USA

Maryam Zamanian MD Clinical Instructor, Division of General Internal Medicine, University of Pittsburgh School of Medicine, Pittsburgh, PA, USA

Galen E Switzer PhD, Professor, Division of General Internal Medicine, University of Pittsburgh School of Medicine, Pittsburgh, PA, Center for Health Equity Research and Promotion (CHERP), Veterans Affairs Pittsburgh Healthcare System, Pittsburgh, PA, USA Competing interests: None.

Funding: JCB receives funding from the Health Resources and Services Administration (HRSA) National Research Service Award (NRSA) for Primary Care Research Award (T32 HP22240). AP receives funding from the National Center for Advancing Translational Sciences of the National Institutes of Health under Award Number TL1TR001858. The content is solely the responsibility of the authors and does not necessarily represent the official views of the National Institutes of Health

Provenance and peer review: Not commissioned, externally peer reviewed.

Correspondence to:

bohnhoffjc@upmc.edu

\section{References}

1. Haggerty JL, Reid RJ, Freeman GK, Starfield BH, Adair CE, McKendry R. Continuity of care: A multidisciplinary review. BMJ 2003;327(7425):1219-21. doi: 10.1136/ bmj.327.7425.1219.
2. Saultz JW, Albedaiwi W. Interpersonal continuity of care and patient satisfaction: A critical review. Ann Fam Med;2(5):445-51. doi: 10.1370/afm.91.

3. Blankfield RP, Kelly RB, Alemagno SA, King CM. Continuity of care in a family practice residency program. Impact on physician satisfaction. J Fam Pract 1990;31(1):69-73.

4. De Maeseneer JM, De Prins L, Gosset C, Heyerick J. Provider continuity in family medicine: Does it make a difference for total health care costs? Ann Fam Med 2003;1(3):144-48. doi: 10.1370/afm.75.

5. Pereira Gray DJ, Sidaway-Lee K, White E, Thorne A, Evans PH. Continuity of care with doctors - a matter of life and death? A systematic review of continuity of care and mortality. BMJ Open 2018;8(6):e021161. doi: 10.1136/bmjopen2017-021161.

6. Murphy M, Salisbury C. Relational continuity and patients' perception of GP trust and respect: A qualitative study. $\mathrm{Br} J$ Gen Pract 2020;70(698):e676-83. doi: 10.3399/ bjgp20X712349.

7. Ball LE, Barnes KA, Crossland L, Nicholson C, Jackson C. Questionnaires that measure the quality of relationships between patients and primary care providers: A systematic review. BMC Health Serv Res 2018;18(1):866. doi: 10.1186/ s12913-018-3687-4.

8. Jee SH, Cabana MD. Indices for continuity of care: A systematic review of the literature. Med Care Res Rev 2006;63(2):158-88. doi: 10.1177/1077558705285294.

9. Jackson C, Ball L. Continuity of care: Vital, but how do we measure and promote it? Aust J Gen Pract 2018;47(10):662-64. doi: 10.31128/AJGP-05-184568.

10. Australian Government Department of Health COVID-19 temporary MBS telehealth services. Canberra, ACT: DoH, 2021. Available at www. mbsonline.gov.au/internet/mbsonline/publishing nsf/Content/Factsheet-TempBB [Accessed 10 May 2021].

11. Hill KM, Twiddy M, Hewison J, House AO. Measuring patient-perceived continuity of care for patients with long-term conditions in primary care. BMC Fam Pract 2014;15:191. doi: 10.1186/s12875014-0191-8.

12. Office of the National Coordinator for Health Information Technology, Office of the Secretary, United States Department of Health and Human Services. 2016 Report to Congress on health IT progress: Examining the HITECH era and the future of health IT. Washington, DC: HHS, 2016.

13. Wrenn G, Kasiah F, Syed I. Using a self-service kiosk to identify behavioural health needs in a primary care clinic serving an urban, underserved population. J Innov Health Inform 2015;22(3):323-28. doi: 10.14236/jhi.v22i3.134.

14. Liu X, Sutton PR, McKenna R, et al. Evaluation of secure messaging applications for a health care system: A case study. Appl Clin Inform 2019;10(1):140-50. doi: 10.1055/s-0039-1678607.

15. Krishnamurti T, Davis AL, Wong-Parodi G, Fischhoff B, Sadovsky Y, Simhan HN. Development and testing of the MyHealthyPregnancy app: A behavioral decision research-based tool for assessing and communicating pregnancy risk. JMIR Mhealth Uhealth 2017;5(4):e42. doi: 10.2196/mhealth.7036.

16. Merchant RA, Hui RJY, Kwek SC, et al. Rapid geriatric assessment using mobile app in primary care: Prevalence of geriatric syndromes and review of its feasibility. Front Med (Lausanne) 20208;7:261. doi: 10.3389/fmed.2020.00261. 